\title{
ATUALIZAÇÃO BASEADA EM EVIDÊNCIAS E CENTRADA NO PACIENTE
}

\section{Flávio Emir Adura e Wanderley Marques Bernardo}

Esta nova seção da RAMB tem como objetivo principal trazer ao leitor, especialista ou generalista, casos clínicos da prática diária, para que sejam discutidos à luz das recomendações do Projeto Diretrizes da AMB e CFM.

Em cada edição da Revista, um especialista convidado, participante da elaboração de diretrizes baseadas em evidências, apresentará um caso clínico, associado a uma série de perguntas, cujas respostas podem ser obtidas na Diretriz AMB-CFM correspondente ao tema abordado. As diretrizes podem ser consultadas nos endereços eletrônicos: www.projetodiretrizes.org.br ou www.amb.org.br, e as respostas às questões clínicas serão disponibilizadas nesta seção, na edição subseqüente.

Faz parte do projeto da RAMB disponibilizar esta seção on-line, em planilha apropriada, para que o leitor possa participar, por meio de suas respostas, de processo educativo continuado, que poderá somar pontos para o Certificado de Atualização Profissional.

Esperamos que cenários clínicos abordando dúvidas em diagnóstico, terapêutica, prognóstico, etiologia ou ética, discutidos frente às recomendações do Projeto Diretrizes, possam contribuir para a disseminação do conhecimento baseado em evidências e centrado no paciente, como também para a atualização e auto-avaliação médica.

\section{TEMA ABORDADO}

Especialidades de abrangência: Medicina de Tráfego, Ginecologia e Obstetrícia, Clínica Médica, Medicina de Urgência, Pediatria, Medicina de Família e Comunidade, Ortopedia e Traumatologia, Medicina Legal.

Diretriz a ser consultada: "O uso do cinto de segurança durante a gravidez"

\section{Cenários e Questões clínicas}

As lesões causadas pelos acidentes de tráfego são as principais causas de mortes por traumatismo, a décima causa de todas as mortes e a nona causa de morbidade em todo o mundo. Muitas destas lesões e mortes podem ser prevenidas por dispositivos de segurança, entre os quais o cinto de segurança ocupa lugar de destaque. Seu uso reduz a mortalidade e a gravidade das lesões provocadas em ocupantes de veículos automotores envolvidos em acidentes.

O uso do cinto de segurança é recomendado para gestantes, mas muitas mulheres grávidas ignoram a forma correta de utilizá-lo, o seu posicionamento e as exigências legais, colocando a si próprias e ao feto em risco. Muitas gestantes pensam que usar o cinto de segurança é perigoso e que pode ser prejudicial para o feto, porém, na realidade, o seu uso confere proteção na imensa maioria das ocasiões. Poucas mulheres são informadas e educadas sobre os efeitos benéficos do uso deste dispositivo de segurança.

Razões alegadas para o não uso do cinto de segurança durante a gravidez incluem o desconforto, medo de prejudicar o feto, esquecimento ou falta de uso habitual. Ademais, muitas das gestantes que se utilizam deste dispositivo de segurança não o ajustam apropriadamente para que o mesmo possa conferir proteção máxima. Outras referem usar o cinto de segurança simplesmente porque é obrigatório por lei. A proximidade do útero gravídico com o airbag aumenta potencialmente o risco de lesões fetais e a forma adequada de utilizá-lo também não é devidamente conhecida.

O uso correto e apropriado destes dispositivos deve ser estimulado e orientado pelos profissionais de saúde. A gestante, quando condutora de veículo automotor, e mesmo na condição de ocupante não condutora do veículo, deverá ser alertada sobre os riscos de lesões traumáticas inerentes ao deslocamento dos veículos e orientadas sobre a maneira de proteger a si própria e ao concepto que abriga em seu útero. 


\section{Questôes}

I) Durante a gravidez, os acidentes de trânsito constituem:

( ) a - a segunda causa mais freqüente de mecanismo de trauma

( ) b - o terceiro motivo mais freqüente de hospitalização

( ) c - a segunda causa de óbito fetal relacionada a trauma materno

( ) d - a primeira causa mais freqüente de mecanismo de trauma e o segundo motivo mais freqüente de hospitalização

( ) e - a etiologia mais freqüente de mecanismo de trauma, o motivo mais freqüente de hospitalização e a principal causa de óbito fetal relacionada a trauma materno

2) Mulheres grávidas que não usam cinto de segurança, quando envolvidas em acidentes de trânsito, podem apresentar:

( ) a - maior probabilidade de gerar filhos com baixo peso ao nascimento e partos 48 horas após o acidente

( ) b - duas vezes mais hemorragias no parto

( ) c - 2,8 vezes mais óbitos fetais

( ) d - ferimentos severos, traumas abdominais intensos e choque hemorrágico

( ) e - todos os eventos acima

3) Entre os efeitos adversos que acometem as gestantes que não usam o cinto de segurança é a complicação mais freqüente:

( ) a - óbito fetal

( ) b - baixo peso ao nascimento

( ) c - descolamento prematuro de placenta

( ) d - rotura uterina

( ) e - prematuridade

4) Em caso de acidente de trânsito envolvendo uma motorista grávida, o principal risco para o feto é:

( ) a - obaixo peso ao nascimento

( ) b - a rotura uterina

( ) c - odescolamento prematuro da placenta

( ) d - a compressão do abdome pela direção do veículo

( ) e - que a mãe tenha ferimentos ou morra

5) A mulher grávida, quando motorista ou passageira de um veículo automotor, deve:

( ) a - usar sempre o cinto de segurança do tipo dois pontos

( ) b - sentar-se sobre a faixa inferior/pélvica (subabdominal) do cinto de segurança e utilizar unicamente a faixa superior/ torácica (diagonal)

( ) c - colocar a faixa superior/torácica (diagonal) do cinto de segurança por trás do tórax e utilizar unicamente a faixa inferior pélvica

( ) d - posicionar a faixa inferior/pélvica (subabdominal) o mais abaixo possível da protuberância abdominal e a faixa diagonal lateralmente ao útero, entre as mamas e no terço médio da clavícula

( ) e - evitar usar o cinto de segurança

6) Em relação ao airbag na gravidez:

( ) a - confere proteção superior à do cinto de segurança

( ) b- seus benefícios superam os riscos, desde que a gestante utilize corretamente o cinto de segurança

( ) c - poderá estar conectado desde que se aproxime o banco para frente

( ) d - está entre as condições médicas que justificam exceções para seu uso

( ) e - deverá ser desconectado

\section{Respostas do cenário clínico "Utilização de Testes Diagnósticos nas Doenças da Tireóide"} (Publicado na Rev Assoc Med Bras 2005; 5 I (5): 253-4)

I-D: No hipotireoidismo central (hipotalâmico ou hipofisário), o TSH não é o exame utilizado para diagnóstico ou monitoração, pois ele pode estar diminuído, normal e até mesmo aumentado. Neste caso, pode haver produção de TSH com atividade biológica diminuída, mas que mantém sua imunoatividade. No hipotireoidismo central, o controle laboratorial deve ser feito com o T4 livre. 2- C: As evidências científicas nos mostram por meio de estudos clínicos bem conduzidos e com bom grau de recomendação que a incidência de alterações nos níveis de TSH e disfunções tireoideanas na população acima dos 35 anos é suficientemente significativa ao ponto de nos permitir tornar a dosagem de TSH a cada cinco anos uma rotina médica nesta faixa etária.

3- D:Na avaliação de auto-imunidade tireoideana, o anticorpo de maior sensibilidade é o antitireoperoxidase (ATPO). Estão presentes em $90-95 \%$ dos indivíduos com tireoidite auto-imune e em $80 \%$ daqueles com doença de Graves. A presença do ATT sozinho, não acompanhado de ATPO, não está significantemente associada a doenças tireoideanas auto-imunes. 